\title{
Influence of Pellet Compaction Pressure on the Physical Properties of $\mathrm{La}_{0.7} \mathrm{Ba}_{0.3} \mathrm{MnO}_{3}$ Manganite
}

\author{
Cintia Raquel Duarte de Freitas ${ }^{a}$, Meirielle Marques de Góis ${ }^{a}$, Rodolfo Bezerra da Silva ${ }^{a}$,
}

\author{
José Alzamir Pereira da Costa ${ }^{a}$ João Maria Soares ${ }^{a}$
}

\author{
${ }^{a}$ Departamento de Física, Universidade do Estado do Rio Grande do Norte, Mossoró RN, 59610-090, \\ Brazil
}

Received: February 16, 2017; Revised: October 01, 2017; Accepted: November 10, 2017

\begin{abstract}
Perovskite manganite $\mathrm{La}_{0.7} \mathrm{Ba}_{0.3} \mathrm{MnO}_{3}$, synthesized by ionic coordination reaction method (ICR) was compacted into pellets under different compaction pressures $\left(\mathrm{P}_{\mathrm{c}}\right)$ and sintered at a temperature of $1150^{\circ} \mathrm{C}$ for $10 \mathrm{~h}$ under a flow of $\mathrm{O}_{2}$. X-ray diffraction (XRD) data reveal that the samples can present simultaneously two phases - a rhombohedral structure with space group R3c and an orthorhombic structure with space group Pnma. Scanning electron microscopy (SEM) images show that, for this sintering temperature, the particle size and shape can be modified depending on the compaction pressure $\left(\mathrm{P}_{\mathrm{c}}\right)$. Magnetization measurements show that the saturation magnetization and Curie temperature increase with $\mathrm{P}_{\mathrm{c}}$. The enhancement of the ferromagnetic properties of perovskite manganites $\mathrm{La}_{0.7} \mathrm{Ba}_{0.3} \mathrm{MnO}_{3}$ as a function of the compaction pressure is explained by an increase in the rhombohedral/orthorhombic structure ratio caused by this effect.
\end{abstract}

Keywords: Reaction by ionic coordination (RCI), compaction pressure

\section{Introduction}

Perovskite-type $\mathrm{RE}_{1-\mathrm{x}} \mathrm{AE}_{\mathrm{x}} \mathrm{MnO}_{3}$, with $\mathrm{RE}$ representing a rare earth and $\mathrm{AE}$ an alkaline earth ion $(\mathrm{AE}=\mathrm{Ca}, \mathrm{Ba}, \mathrm{Sr}$ and $\mathrm{Pb}$ ), has attracted great scientific interest because of its peculiar physical properties and potential technological applications such as magnetic recording, magnetic heating and switch control in hyperthermia treatment, refrigerating materials, and as a cathode in solid oxide fuel cells (SOFCs) ${ }^{1-6}$. Its fundamental properties show a strong correlation between crystal structure and chemical composition, and it displays features such as electronic transport and magnetic properties. The $\mathrm{LaMnO}_{3}$ compound is an A-type antiferromagnetic material with Neel temperature $T_{N}=140$ $\mathrm{K}$, having an orthorhombic structure and space group Pnma, and at this stoichiometry the Mn element has valence $(3+)^{5}$. The partial substitution of the trivalent element $\left(\mathrm{La}^{3+}\right)$ at the A site by divalent elements leads these compounds to present valence mixing in the metal element at the $\mathrm{B}$ site of its $\mathrm{ABO}_{3}$ type structure. In this case, the manganese has valences $(3+)$ and $(4+)$, causing the existence of bonds of type $\mathrm{Mn}^{3+}-\mathrm{Mn}^{3+}$ and $\mathrm{Mn}^{3+}-\mathrm{Mn}^{4+}$. This valence mixture is responsible for strengthening of effects such as colossal magnetoresistance (CMR) and the magnetocaloric effect (MCE) in manganites ${ }^{6}$. The $\mathrm{La}_{1-\mathrm{x}} \mathrm{Ba}_{\mathrm{x}} \mathrm{MnO}_{3}$ compounds have a high concentration of vacancies in both $\mathrm{A}(\mathrm{La} /$ $\mathrm{Ba}$ ) and $\mathrm{B}(\mathrm{Mn})$ sites, which gives rise to large localized distortions, influencing the physical properties of the

*e-mail: rodolfo.bezerra.silva@gmail.com material ${ }^{7-11}$. It has been shown that in samples of type $\mathrm{La}_{2 / 3} \mathrm{Ba}_{1 / 3} \mathrm{MnO}_{3}$ the crystal-structure parameters such as mean bond length $<\mathrm{Mn}-\mathrm{O}>$ and the mean bond angle $<\mathrm{Mn}-\mathrm{O}-\mathrm{Mn}>$ are factors determining the properties of the manganites ${ }^{12,13}$. Usually this variation leads to an increase in electron bandwidth that can strongly modify the Curie temperature and the metal-to-insulator transition temperature as well as decreasing the resistivity ${ }^{12,13}$. Reported studies in the literature show that manganite properties such as insulator to metal transition temperature $\mathrm{T}_{\mathrm{IM}}$, Curie temperature $\left(T_{\mathrm{C}}\right)$, charge ordering $(\mathrm{CO})$ and magnetization can have a strong dependence on an applied hydrostatic pressure $^{13-17}$. Although several studies have been carried out on manganites as a function of hydrostatic pressure, we have not found any paper reporting studies on the effect of compaction pressure on the physical properties of the pellet samples. The compaction pressure used to form the pellets before sintering can also be an important parameter affecting the magnetic and electron transport properties of manganites. Therefore, we decided to study the possible effects on the structural and magnetic properties of the manganite $\mathrm{La}_{0.7} \mathrm{Ba}_{0.3} \mathrm{MnO}_{3}$ synthesized by the chemical method of ionic coordination reaction (ICR), preparing pellets under compaction pressures of $3.7 \times 10^{2}, 6.2 \times 10^{2}$ and $8.7 \times 10^{2} \mathrm{MPa}$. The crystal-structure and microstructural parameters, average particle sizes, micro deformation, lattice parameters and some magnetic properties were studied. We show that the compaction pressure modified the crystalline perovskite structure, the values of lattice parameters and magnetic properties. 


\section{Experimental}

Perovskite $\mathrm{La}_{0.7} \mathrm{Ba}_{0.3} \mathrm{MnO}_{3}$ was synthesized by an ionic coordination reaction method ${ }^{18}$. For the synthesis we used the nitrates $\mathrm{La}\left(\mathrm{NO}_{3}\right)_{3} \cdot 9 \mathrm{H}_{2} \mathrm{O}, \mathrm{Ba}\left(\mathrm{NO}_{3}\right)_{2}$, and $\mathrm{Mn}\left(\mathrm{NO}_{3}\right)_{3} \cdot 4 \mathrm{H}_{2} \mathrm{O}$, which were added to an aqueous solution of chitosan based polymer. The chitosan based solution was prepared by dissolving 5\% citric acid in $500 \mathrm{ml}$ of distilled water and then adding $2 \%$ chitosan, and maintained under magnetic stirring for $24 \mathrm{~h}$. After this period the solution was filtered to remove excess chemicals. The $\mathrm{La}, \mathrm{Ba}$ and $\mathrm{Mn}$ nitrates were added, under magnetic stirring, to the chitosan solution in the desired stoichiometry (0.7La:0.3Ba:1.0Mn). Once this new solution was homogenized, $10 \%$ by volume of glutaraldehyde was added. After 2 hours at room temperature the solution became gelled. The gel was thermally treated on a hot plate for 8 hours at an average temperature of 150 ${ }^{\circ} \mathrm{C}$. The calcined powder was used to produce a set of three pellets using a $10 \mathrm{~mm}$ diameter cylindrical pelletizer with compaction pressures of $3.7 \times 10^{2}, 6.2 \times 10^{2}$ and $8.7 \times 10^{2} \mathrm{MPa}$. The pellets were sintered in a tubular furnace at a temperature of $1150{ }^{\circ} \mathrm{C}$ for 10 hours in a flow of $\mathrm{O}_{2}$. The three sintered samples were named $\mathrm{LBM}_{3.7}, \mathrm{LBM}_{6.2}$ and $\mathrm{LBM}_{8.7}$. X-ray diffraction (XRD) patterns of these pellets were obtained using a Rigaku diffractometer, model Mini flex II with $\mathrm{Cu}$ $\mathrm{K}_{\alpha}$ radiation, using a scan step size of $0.02^{\circ}$ and scan speed of $1 \% \mathrm{~min}$. The average size of the crystallites and crystal structure were obtained by the Rietveld method using Maud software ${ }^{19,20}$. The morphologies were observed by scanning electron microscopy (SEM), using a Tescan-MIRA3 LMU microscope. Zero field cooled (ZFC) and field cooled (FC) measurements of the magnetic hysteresis loops measurements were performed in a vibrating sample magnetometer (VSM). For the ZFC magnetization curve, the sample is first cooled in a zero field from a high temperature down to a low temperature. Then the magnetic field is applied and the magnetization as a function of temperature is measured in the warming process. The FC curve is obtained by cooling the sample to the low temperature in the same magnetic field, then measuring magnetization versus temperature in the warming process.

\section{Results and Discussion}

\subsection{Structural Analysis (XRD) and (SEM)}

X-ray diffraction (XRD) patterns for samples $\mathrm{LBM}_{3,7} \mathrm{LBM}_{6,2}$ and $\mathrm{LBM}_{8.7}$ are shown in Figure 1. The formation of crystalline phases of $\mathrm{La}_{0.7} \mathrm{Ba}_{0.3} \mathrm{MnO}_{3}$ perovskite is observed in the XRD patterns, but no other phase is observed within the resolution of the X-ray diffraction. The Rietveld refinement data show that samples $\mathrm{LBM}_{3.7}$ (figure 1(A)) and $\mathrm{LBM}_{6.2}$ (figure 1(B)) present two perovskite structures, a rhombohedral structure with space group R3c and an orthorhombic structure with space group Pnma. Figure 1(C) shows that sample $\mathrm{LBM}_{8.7}$ only has the rhombohedral structure with space group R3c.

Table 1 shows the crystalline parameters, obtained by Rietveld refinements, for all samples. These data reveal that the compaction pressure can be used to control the types of crystalline structure. The values of the $a$ and $c$ lattice parameters obtained by Rietveld refinements for all samples are very close to values already reported for bulk samples ${ }^{21}$. The inserts in figures 1 (A)-(B) show details of the (024) peak for the rhombohedral structure and of the (040) and (202) peaks for the orthorhombic structure for samples $\mathrm{LBM}_{3.7}$ and $\mathrm{LBM}_{6.2}$, respectively. For sample $\mathrm{LBM}_{8.7}$, the insert in figure $1(\mathrm{C})$ shows that peak at $2 \theta=46.48^{\circ}$ was refined only as the rhombohedral crystalline structure.

Figure 2 shows images from scanning electron microscopy (SEM) for samples $\mathrm{LBM}_{3.7}, \mathrm{LBM}_{6.2}$ and $\mathrm{LBM}_{8.7}$, using two magnifications. In figures 2(a)-(c) we show the SEM micrographs with magnifications of $304-306 x$, which show the microstructure of the pellet surfaces.

Low porosity can be observed, indicating that the compaction process and heat treatment were enough to produce a relatively homogeneous sample surface.

Analyzing the images we see an indication that the pellet compaction pressure can be an important parameter since it clearly modified the surfaces of the samples. Sample $\mathrm{LBM}_{8.7}$, made with an applied pressure of $8.7 \times 10^{2} \mathrm{MPa}$, shows a smoother surface, indicating a good sintering effect on the material.

Table 1. Refined structural parameters of XRD: Weight wt, lattice parameters a, b and c, weighted - profile $\mathrm{R}_{\mathrm{wt}}$ and goodness of fit $\chi^{2}$ for samples $\mathrm{LBM}_{3.7}, \mathrm{LBM}_{6.2}$ and $\mathrm{LBM}_{8.7}$.

\begin{tabular}{|c|c|c|c|}
\hline Sample Group & Space & $\mathrm{R} 3 \mathrm{c}$ & Pnma \\
\hline \multirow{7}{*}{$\mathbf{L B m}_{3.7}$} & Wt (\%) & 74.8 & 25.2 \\
\hline & $\mathrm{a}(\AA)$ & 5.5218 & 5.5143 \\
\hline & $\mathrm{b}(\AA)$ & 5.5218 & 7.7874 \\
\hline & $\mathrm{c}(\AA)$ & 13.4646 & 5.5046 \\
\hline & $\chi^{2}$ & 1.129 & - \\
\hline & $\mathrm{R}_{\mathrm{wp}}$ & $20.21 \%$ & - \\
\hline & $\mathrm{Wt}(\%)$ & 83.9 & 16.1 \\
\hline \multirow{6}{*}{$\mathbf{L B M}_{6.2}$} & a $(\AA)$ & 5.5253 & 5.5078 \\
\hline & $\mathrm{b}(\AA)$ & 5.5253 & 7.8073 \\
\hline & $\mathrm{c}(\AA)$ & 13.5847 & 5.5311 \\
\hline & $\chi^{2}$ & 1.052 & - \\
\hline & $\mathrm{R}_{\mathrm{wp}}$ & $20.47 \%$ & - \\
\hline & Wt (\%) & 100 & - \\
\hline \multirow{5}{*}{$\mathbf{L B M}_{8.7}$} & $\mathrm{a}(\AA)$ & 5,5291 & - \\
\hline & b $(\AA)$ & 5.5291 & - \\
\hline & $\mathrm{c}(\AA)$ & 13.4891 & - \\
\hline & $\chi^{2}$ & 0.968 & - \\
\hline & $\mathrm{R}_{\mathrm{wp}}$ & $17.81 \%$ & - \\
\hline
\end{tabular}



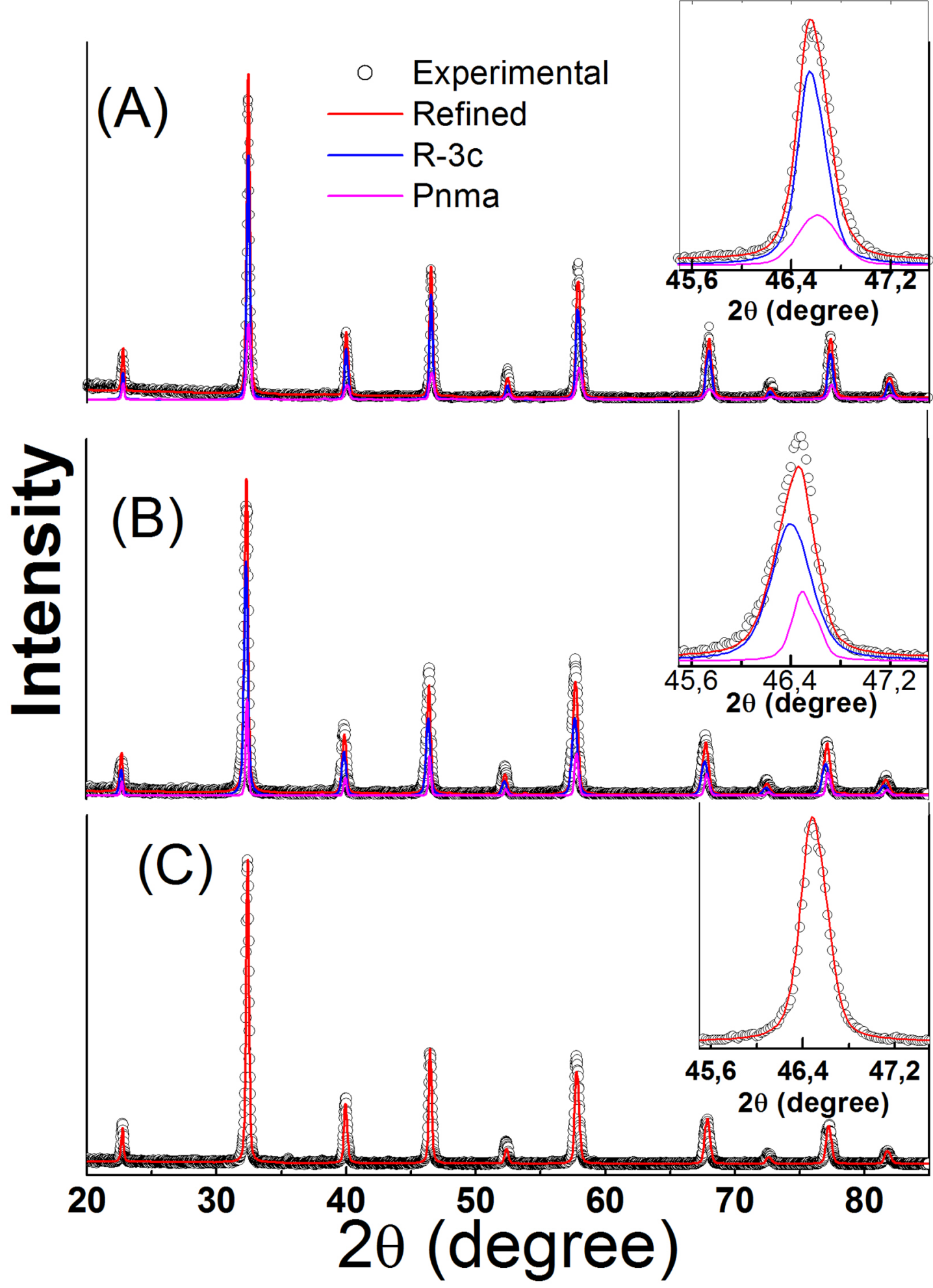

Figure 1. XRD patterns for pellet samples of $\mathrm{LBM}_{3,7}, \mathrm{LBM}_{62}$ and $\mathrm{LBM}_{87}$ calcined at $1150{ }^{\circ} \mathrm{C} / 10 \mathrm{~h}$. The open points and lines are experimental data and fitting of the XRD, respectively. The inserts show details of the peaks localized $2 \theta=46-47.3$. 


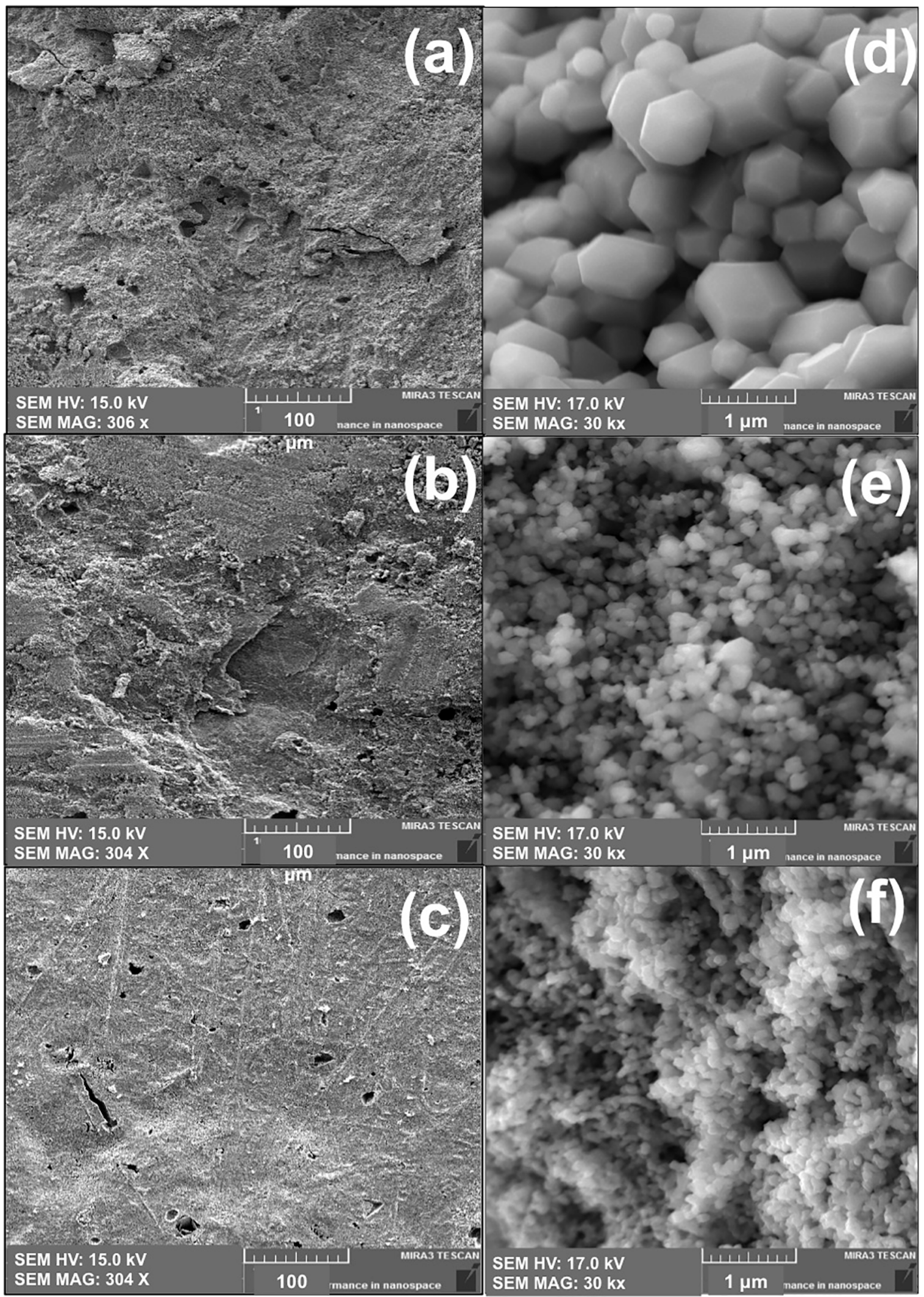

Figure 2. (a) - (c) SEM micrographs for pellet Sample (a) $\mathrm{LBM}_{3.7}$, (b) $\mathrm{LBM}_{6.2}$ and (c) $\mathrm{LBM}_{8.7}$ with Magnification of 300x, (d) - (f) SEM micrographs for Pellet Sample (a) $\mathrm{LBM}_{3,7}$, (b) $\mathrm{LBM}_{6,2}$ and (c) $\mathrm{LBM}_{8.7}$ with Magnification of $30 \mathrm{kx}$. 


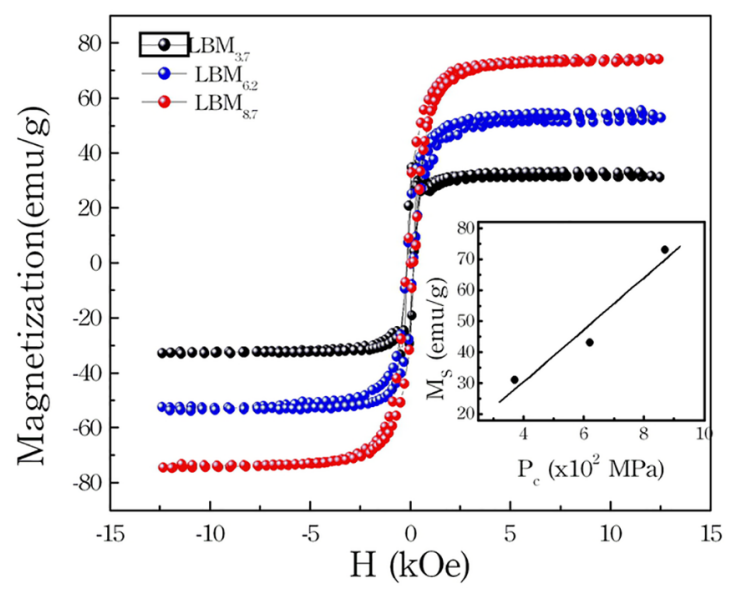

Figure 3. Magnetic hysteresis loop for the samples $\mathrm{LBM}_{3.7}, \mathrm{LBM}_{6.2}$ and $\mathrm{LBM}_{87}$ Measured at $10 \mathrm{~K}$. The inset shows the saturation magnetization $(\mathrm{T}=10 \mathrm{~K})$ in function of compaction pressure.

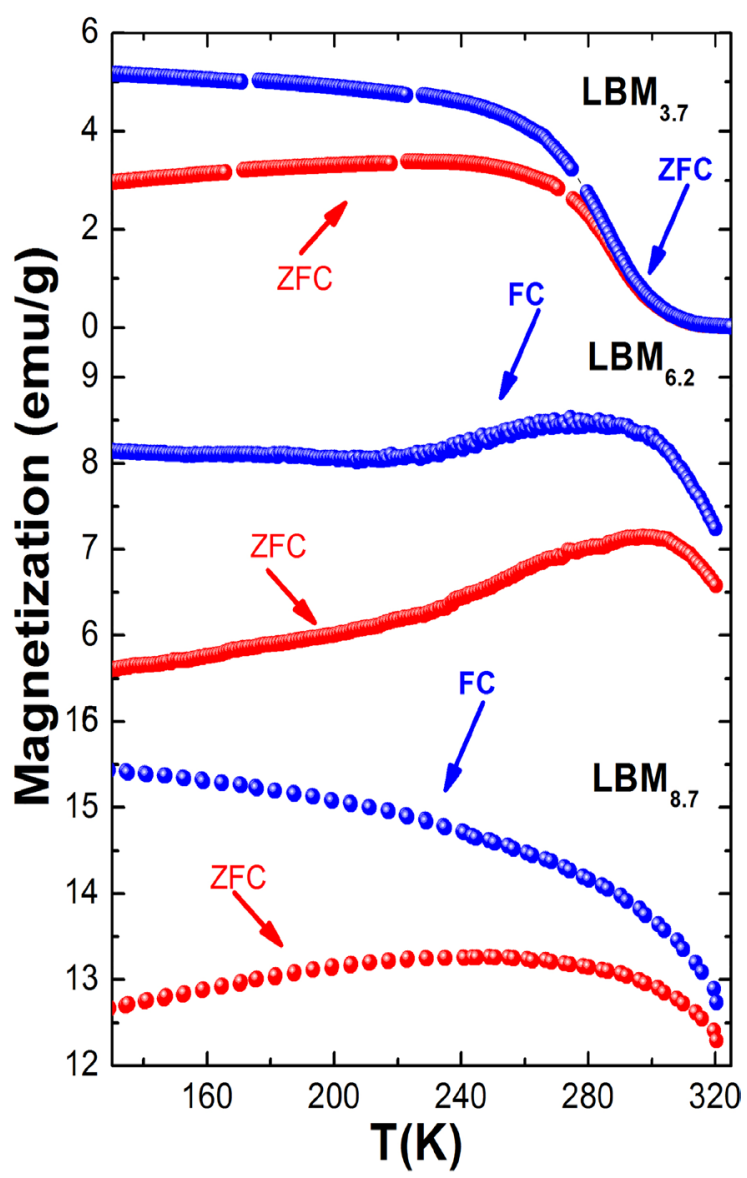

Figure 4. Field Cooled and Zero Field Cooled Magnetizations for Samples LBM3.7, LBM6.2 and LBM8.7.

Figures 2 (d)-(f) show SEM images with magnification of $30 \mathrm{kx}$ for all the samples analyzed. We observe that sample $\mathrm{LBM}_{3.7}$ consists of crystallites with sizes ranging from 0.50 $1.82 \mu \mathrm{m}$ with a mean crystallite size of $1.11 \mu \mathrm{m}$. For samples $\mathrm{LBM}_{6.2}$ and $\mathrm{LBM}_{8.7}$, the average diameters obtained directly from the SEM pictures (figures 2(e)-(f)) were $126 \mathrm{~nm}$ and $108 \mathrm{~nm}$, respectively.

We believe that this effect occurs in the synthesizing process in which metallic ions of the nitrates are bound to the chitosan chain. Due to the action of the glutaraldehyde, this then forms a cross-linked chain agglomerate, trapping the metal ions in very narrow spaces. The applied pressure on the pre-calcined powder breaks down the agglomerates into smaller parts that will form the crystallites during the sintering process. We conclude that the increase of compaction pressure $P_{c}$ decreases the average size of crystallites in the sintered samples. Thus, the larger the $P_{c}$ value the smaller the particle sizes that make up the resulting $\mathrm{La}_{0.7} \mathrm{Ba}_{0.3} \mathrm{MnO}_{3}$ manganite. In addition, the effect of compaction pressure causes a decrease in the unit cell volume $\mathrm{V}$, which leads to a decrease in the $<\mathrm{Mn}-\mathrm{O}>$ bond length and to an increase in the $<\mathrm{Mn}-\mathrm{O}-\mathrm{Mn}>$ bond angles influencing the physical properties of the material.

\subsection{Magnetization Measurements}

Figure 3 shows the magnetic hysteresis curves at a temperature of $10 \mathrm{~K}$ for samples $\mathrm{LBM}_{3.7}, \mathrm{LBM}_{6.2}$ and $\mathrm{LBM}_{8.7}$. From the curves we observe ferromagnetic (FM) behavior for all samples. Sample $\mathrm{LBM}_{3.7}$ has the lowest value of the saturation magnetization $\mathrm{M}_{\mathrm{s}}=31 \mathrm{emu} / \mathrm{g}$, while samples $\mathrm{LBM}_{6.2}$ and $\mathrm{LBM}_{8.7}$ exhibit $\mathrm{M}_{\mathrm{S}}$ values of 43 and $73 \mathrm{emu} / \mathrm{g}$, respectively. The value of $\mathrm{M}_{\mathrm{S}}$ for sample $\mathrm{LBM}_{3.7}$ is very close to the value obtained by Kundu et al. ${ }^{22}$ for $\mathrm{La}_{0.7} \mathrm{Ba}_{0.3} \mathrm{MnO}_{3}$ samples indexed as having an orthorhombic structure with the Pnma space group, whereas, for sample $\mathrm{LBM}_{8,7}$, the higher $\mathrm{M}_{\mathrm{S}}$ value is near the value of approximately $80 \mathrm{emu} / \mathrm{g}^{23}$ obtained for a rhombohedral structure with space group $\mathrm{R} 3 \mathrm{c}^{23-25}$. The insert in figure 3 shows that the saturation magnetization increases proportionally with compaction pressure. ZFC and FC magnetization vs temperature measurements under a field of $100 \mathrm{Oe}$ areshown in figure 4 . The Curie temperature $T_{\mathrm{C}}$, corresponding to a ferromagnetic to paramagnetic transition, is defined as the temperature corresponding to the minimum of the first derivative of the $\mathrm{M}(\mathrm{T})$ curve. The results of MxT indicate that the value of the transition temperature $\mathrm{T}_{\mathrm{C}}$ increases with compaction pressure.

For the sample $\mathrm{LBM}_{3.7}$ a Curie temperature of $T_{\mathrm{C}}=288 \mathrm{~K}$ was obtained. However, for samples $\mathrm{LBM}_{6.2}$ and $\mathrm{LBM}_{8.7}$ the $T_{\mathrm{C}}$ values are greater than the maximum measurable temperature with VSM, T $=320 \mathrm{~K}$. The increase in the value of $\mathrm{M}_{\mathrm{S}}$ and $T_{\mathrm{C}}$ can be explained by an increase in the amount of rhombohedral crystalline phase with increasing $\mathrm{P}_{\mathrm{c}}$, which favors a ferromagnetic behavior.

\section{Conclusion}

We have investigated the influence of compaction pressure $\left(\mathrm{P}_{\mathrm{c}}\right)$ on the physical properties of $\mathrm{La}_{0.7} \mathrm{Ba}_{0.3} \mathrm{MnO}_{3}$ perovskite. XRD results showed that the samples are formed 
by two coexisting phases, one with a rhombohedral structure and other with an orthorhombic structure. The increase of the compaction pressure favored the formation of the rhombohedral crystalline structure. The SEM analysis shows that there is little porosity, indicating that the compaction and heat treatment were enough to produce homogeneus material. The SEM micrographs shown that the average size of crystallites decreases from $1110 \mathrm{~nm}$ to $108 \mathrm{~nm}$ with increasing $\mathrm{P}_{\mathrm{c}}$. Magnetic measurements show a typical behavior for a ferromagnetic material at temperatures below $T_{\mathrm{C}}$. In addition, an increase in the compaction pressure causes an increase in the saturation magnetization from 31 to 73 $\mathrm{emu} / \mathrm{g}$ and in the Curie temperature, as shown through the ZFC/FC measurements.

\section{Acknowledgement}

This work was partially supported by the Brazilian agencies $\mathrm{CNPq}$ and CAPES.

\section{References}

1. Moreira ML, Soares JM, de Azevedo WM, Rodrigues AR, Machado FLA, de Araújo JH. Structural and magnetic properties of nanoparticles of $\mathrm{La}_{2 / 3} \mathrm{Sr}_{1 / 3} \mathrm{MnO}_{3}$. Physica B: Condensed Matter. 2006;384(1-2):51-53.

2. Ramirez AP. Colossal magnetoresistance. Journal of Physics: Condensed Matter. 1997;9(39):8171-8199.

3. Das S, Dhak D, Reis MS, Amaral VS, Dey TK. Room temperature giant magnetoimpedance in $\mathrm{La}_{0.7} \mathrm{Ba}_{0.15} \mathrm{Sr}_{0.15} \mathrm{MnO}_{3}$ compound. Materials Chemistry and Physics. 2010;120(2-3):468-471.

4. Daivajna MD, Kumar N, Awana VPS, Gahtori B, Christopher $\mathrm{JB}$, Manjunath SO, et al. Electrical, magnetic and thermal properties of $\mathrm{Pr}_{0.6-\mathrm{x}} \mathrm{Bi}_{\mathrm{x}} \mathrm{Sr}_{0.4} \mathrm{MnO}_{3}$ manganites. Journal of Alloys and Compounds. 2014;588:406-412.

5. Oumezzine M, Kallel S, Peña O, Kallel N, Guizouarn T, Gouttefangeas F, et al. Correlation between structural, magnetic and electrical transport properties of barium vacancies in the $\mathrm{La}_{0.67} \mathrm{Ba}_{0.33-\mathrm{x} ? \mathrm{x}} \mathrm{MnO}_{3}(\mathrm{x}=0,0.05$, and 0.1) manganite. Journal of Alloys and Compounds. 2014;582:640-646.

6. Muñoz D, Harrison NM, Illas F. Electronic and magnetic structure of $\mathrm{LaMnO}_{3}$ from hybrid periodic density-functional theory. Physical Review B. 2004;69(8):085115.

7. Dabrowski B, Rogacki K, Xiong X, Klamut PW, Dybzinski R, Shafler J, et al. Synthesis and properties of the vacancy-free $\mathrm{La}_{1-\mathrm{x}} \mathrm{Ba}_{\mathrm{x}} \mathrm{MnO}_{3}$. Physical Review B. 1998;58(5):2716.

8. Van Roosmalen JAM, Cordfunk EHP. The Defect Chemistry of $\mathrm{LaMnO}_{3 \pm d}: 3$. The Density of $(\mathrm{La}, \mathrm{A}) \mathrm{MnO}_{3+\mathrm{d}}(\mathrm{A}=\mathrm{Ca}, \mathrm{Sr}$, Ba). Journal of Solid State Chemistry. 1994;110(1):106-108.

9. Toepfer J, Goodenough JB. Transport and Magnetic Properties of the Perovskites $\mathrm{La}_{1-\mathrm{y}} \mathrm{MnO}_{3}$ and $\mathrm{LaMn}_{1-\mathrm{z}} \mathrm{O}_{3}$. Chemistry of Materials. 1997;9(6): $1467-1474$.
10. Van Roosmalen JAM, Cordfunke EHP. The Defect Chemistry of $\mathrm{LaMnO}_{3 \pm \delta}: 3$. The Density of $(\mathrm{La}, A) \mathrm{MnO}_{3+\delta}(A=\mathrm{Ca}, \mathrm{Sr}$, Ba). Journal of Solid State Chemistry. 1994; 110(1):106-108.

11. Hervieu M, Mahesh R, Rangavittal N, Rao CNR. Deffect Structure of $\mathrm{LaMnO}_{3}$. European Journal of Solid State and Inorganic Chemistry. 1995;32(2):79-94.

12. Moritomo Y, Asamitsu A, Tokura Y. Pressure effect on the double-exchange ferromagnet $\mathrm{La}_{1-\mathrm{x}} \mathrm{Sr}_{\mathrm{x}} \mathrm{MnO}_{3}(0.15=\mathrm{x}=0.5)$. Physical Review B. 1995;51(22):16491(R).

13. Moritomo Y, Asamitsu A, Tokura Y. Enhanced electronlattice coupling in $\mathrm{La}_{1-\mathrm{x}} \mathrm{Sr}_{\mathrm{x}} \mathrm{MnO}_{3}$ near the metal-insulator phase boundary. Physical Review B. 1997;56(19):12190.

14. Tissen VG, Ponyatovskii EG, Nefedova MV, Laukhin V, Martínez B, Fontcuberta J, et al. Charge ordering and phase transformations in low-doped $\mathrm{La}_{1-\mathrm{x}} \mathrm{Sr}_{\mathrm{x}} \mathrm{MnO}_{3}$ single crystals under pressures up to $70 \mathrm{kbar}$. Journal of Magnetism and Magnetic Materials. 2000;211(1-3):145-149.

15. Kamenev K, Balakrishnan G, Lees MR, Paul DMcK, Arnold $\mathrm{Z}$, Mikulina $\mathrm{O}$. Influence of pressure on structural and magnetic phase transitions in $\mathrm{La}_{0.835} \mathrm{Sr}_{0.165} \mathrm{MnO}_{3}$. Physical Review B. 1997;56(5):2285.

16. Postorino P, Congeduti A, Dore P, Sacchetti A, Gorelli F, Ulivi L, et al. Pressure Tuning of Electron-Phonon Coupling: The Insulator to Metal Transition in Manganites. Physical Review Letters. 2003;91(17):175501.

17. Thiyagarajan R, Esakki Muthu S, Mahendiran R, Arumugam S. Effect of hydrostatic pressure on magnetic and magnetocaloric properties of $\mathrm{Mn}$-site doped perovskite manganites $\operatorname{Pr}_{0.6} \mathrm{Ca}_{0.4} \mathrm{Mn}_{0.96} \mathrm{~B}_{0.04} \mathrm{O}_{3}(\mathrm{~B}=\mathrm{Co}$ and $\mathrm{Cr})$. Journal of Applied Physics. 2014;115(4):043905.

18. Soares JM, Machado FLA, de Araujo JH, Cabral FAO, Rodrigues HAB, Ginani MF. Anisotropy field and transverse susceptibility in nanocrystalline hexaferrites. Physica B: Condensed Matter. 2006;384(1-2):85-87.

19. Lutterotti L, Matthies S, Wenk HR. MAUD (material analysis using diffraction): a user friendly Java program for Rietveld texture analysis and more. In: Proceedings of the Twelfth International Conference on Textures of Materials (ICOTOM-12); 1999 Aug 9-13; Montreal, Canada.

20. Ferrari M, Lutterotti L. Method for the simultaneous determination of anisotropic residual stresses and texture by $\mathrm{x}$-ray diffraction. Journal of Applied Physics. 1994;76(11):7246.

21. Radaelli PG, Marezio M, Hwang HY, Cheong SW. Structural Phase Diagram of Perovskite $\mathrm{A}_{0.7} \mathrm{~A}_{0.3}^{\prime} \mathrm{MnO}_{3}\left(\mathrm{~A}=\mathrm{La}, \mathrm{Pr} ; \mathrm{A}^{\prime}=\mathrm{Ca}, \mathrm{Sr}\right.$, $\mathrm{Ba})$ : A New Imma Allotype. Journal of Solid State Chemistry. 1996;122(2):444-447.

22. Kundu AK, Seikh MM, Ramesha K, Rao CNR. Novel effects of size disorder on the electronic and magnetic properties of rare earth manganates of the type $\mathrm{La}_{07-\mathrm{x}} \mathrm{Ln}_{\mathrm{x}} \mathrm{Ba}_{03} \mathrm{MnO}_{3}$ $(\mathrm{Ln}=\mathrm{Pr}, \mathrm{Nd}, \mathrm{Gd}$ or Dy) with large average radius of the A-site cations. Journal of Physics: Condensed Matter. $2005 ; 17(26): 4171$. 
23. Fu Q, Zhou L, Zhou D, Miao L, Chen C, Xue F. Large magneto-electric effects in hexagonal $\mathrm{La}_{0.7} \mathrm{Ba}_{0.3} \mathrm{MnO}_{3}-\mathrm{BaTiO}_{3}$ solid solutions and magneto-electric coupling mechanism discussion. Journal of Applied Physics. 2014;116(13):134103. DOI: $10.1063 / 1.4897200$
24. Ju HL, Nam YS, Lee JE, Shin HS. Anomalous magnetic properties and magnetic phase diagram of $\mathrm{La}_{1-\mathrm{x}} \mathrm{Ba}_{\mathrm{x}} \mathrm{MnO}_{3}$. Journal of Magnetism and Magnetic Materials. 2000;219(1):1-8.

25. Im HS, Chon GB, Lee SM, Koo BH, Lee CG, Jung MH. Preparation and characterization of $\mathrm{La}_{0.7} \mathrm{AE}_{0.3} \mathrm{MnO}_{3}(\mathrm{AE}=\mathrm{Ca}$, $\mathrm{Sr}, \mathrm{Ba})$ : Perovskite structured manganite. Journal of Magnetism and Magnetic Materials. 2007;310(2 Pt 3):2668-2670. 